\title{
Rectal epithelial apoptosis in familial adenomatous polyposis patients treated with sulindac
}

J J Keller, G J A Offerhaus, M Polak, S N Goodman, M L Zahurak, L M Hylind, S R Hamilton, F M Giardiello

\begin{abstract}
Background-Sulindac regresses colorectal adenomas in patients with familial adenomatous polyposis (FAP), although the mechanism of polyp regression is unclear.

Aims-To determine whether differences occur in alteration of rectal epithelial apoptotic index and expression of apoptosis related proteins in FAP patients treated with sulindac compared with placebo.
\end{abstract}

Patients-Twenty one FAP patients; 12 had not undergone colectomy.

Methods-Patients with FAP were treated with sulindac $150 \mathrm{mg}$ orally twice a day for three months $(n=10)$ or placebo $(n=11)$. Colorectal polyp number was determined and biopsies of the normal rectal mucosa were performed before and after three months of treatment. Response to treatment and alteration of the apoptotic ratio (index in base of crypt divided by index in surface epithelium) were evaluated. Bcl-2, bax, p21/WAF-1, and p53 proteins were assessed semiquantitatively by immunohistochemistry.

Results-Significant decreases in polyp number and in the apoptotic ratio were seen in patients treated with sulindac compared with controls. The mean percentage change in polyp number from baseline was $-46 \%$ in the sulindac group and $+13 \%$ in the placebo group $(p=0.005)$. Mean percentage change in the apoptotic ratio was $-8 \%$ and $+25 \%$ in the sulindac and placebo treated patients, respectively $(p=0.004)$. No differences in expression or compartmentalisation of apoptosis related proteins were noted between treatment groups.

Conclusions-Sulindac regression of colorectal adenomas is accompanied by alteration of the rectal epithelial apoptotic ratio with relative increase in apoptosis in surface cells compared with the deeper crypt. The utility of the apoptotic ratio as an intermediate biomarker for colorectal tumorigenesis deserves further study. (Gut 1999;45:822-828)

Keywords: apoptosis; familial adenomatous polyposis; sulindac; intermediate biomarker; tumorigenesis

Multiple lines of investigation support the concept that non-steroidal anti-inflammatory drugs (NSAIDs) such as aspirin can prevent colorectal cancer. ${ }^{1}$ Specifically, NSAIDs inhibit cell growth in cell culture, ${ }^{2-4}$ decrease the multiplicity and incidence of colon tumours in carcinogen induced murine models, ${ }^{5-9}$ and decrease the relative risk of incidence and mortality of colorectal cancer in human epidemiological studies. ${ }^{10}{ }^{11}$ In addition, investigators have shown that the NSAID sulindac can induce regression of adenomas in patients with familial adenomatous polyposis (FAP), an autosomal dominant disorder characterised by the formation of hundreds of colorectal adenomas and the subsequent development of colorectal cancer. ${ }^{12-16}$

The mechanism of action of NSAIDs in chemoprevention of colorectal cancer is unknown. Colorectal epithelial homoeostasis normally results from a balance between the rate of cell proliferation and the rate of cell loss from apoptosis. Proliferating cells are restricted to the lower third of the crypt, ${ }^{17}$ whereas apoptosis occurs principally at the luminal surface of the epithelium. ${ }^{18-20}$ Several investigators have shown that transformation of colorectal epithelium to adenoma and then carcinoma is associated with progressive inhibition of apoptosis ${ }^{21}$ and changes in the compartmentalisation of proliferation and apoptosis. ${ }^{20}{ }^{22}$ Also, proteins such as p21/WAF-1, bcl-2, bax, and p53 which are known to be associated with cell cycle regulation and apoptosis, have distinctive colorectal epithelial expression and compartmentalisation ${ }^{23}{ }^{24}$; alterations in these markers have been noted in colorectal carcinogenesis. ${ }^{25-27}$ In familial adenomatous polyposis, alterations in proliferation and apoptosis are present in the grossly normal appearing flat colorectal mucosa, ${ }^{17} 2128$ and consequently this syndrome serves as a model to study early changes in the adenomacarcinoma sequence.

Previous studies on the effects of sulindac on colonic epithelial proliferation in patients with FAP have shown that sulindac does not affect colorectal epithelial proliferation, ${ }^{29}{ }^{30}$ although one investigation has reported a decrease. ${ }^{16} \mathrm{On}$ the other hand, adenoma regression by sulindac seems to be associated with increased apoptosis in FAP patients ${ }^{29}$ and in the MIN mouse model of FAP. ${ }^{31}$ Furthermore, sulindac induces apoptosis in cell culture models. ${ }^{32}$

Abbreviations used in this paper: AI, apoptotic index; AR, apoptotic ratio; FAP, familial adenomatous polyposis; NSAID, non-steroidal anti-inflammatory drug. 
Therefore, we investigated the effects on apoptosis in individual crypt compartments of grossly normal appearing flat rectal epithelium of FAP patients treated with sulindac compared with placebo. The expression and compartmentalisation of apoptosis related protein expression were also analysed in these two patient groups.

\section{Methods}

SUBJECTS

Patients with FAP were enrolled in a randomised, double blind, placebo controlled trial to determine the effect of sulindac on colorectal adenomas, as reported previously. ${ }^{15}$ Twenty one patients from the larger initial study population (12 who had not undergone colectomy) with adequate colorectal mucosal samples at time 0 and three months were analysed in this study. Informed consent was obtained from all patients, and the protocol was approved by The Johns Hopkins University Joint Committee on Clinical Investigation (institutional review board). Ten patients (three men, seven women; mean age 26.5 (SD 10.1) years, range 13-45) received $150 \mathrm{mg}$ sulindac by mouth twice a day for three months. Eleven patients (six men, five women; mean age 22.7 (8.7) years, range 16-51) took identical placebo tablets for three months. Compliance with medication was assessed by pill count and was universally greater than $85 \%$. At time 0 and 3 months, rectal polyp number was assessed by flexible sigmoidoscopy using an Olympus flexible video sigmoidoscope. At time 0 the colorectal mucosa was tattooed with sterile India ink about $20 \mathrm{~cm}$ from the anal verge. The endoscopist counted total polyp number in the entire circumference of colorectum from the tattoo mark to anal verge and recorded the examination on videotape. There were no significant differences in the demographic and clinical characteristics between treatment groups.

All patients were prepared for each endoscopic procedure with a clear liquid diet and oral cathartic solution. Enemas which could influence mucosal biochemistry were not given. In each patient, during flexible sigmoidoscopy, six rectal mucosal biopsy specimens were taken from flat mucosa $10-12 \mathrm{~cm}$ from the anal verge to minimise potential differences which might occur from specimens taken at different colorectal sites. Rectal mucosal specimens were snap frozen in liquid nitrogen or placed in formalin or methanol, and embedded in paraffin wax for histopathological examination.

DETECTION OF APOPTOSIS

Apoptotic cell death was assessed by light microscopy in a blinded fashion, with examination of coded haematoxylin and eosin stained slides from biopsy specimens of the grossly normal colorectal mucosa by two observers (GJAO, JJK) as utilised previously. ${ }^{19} 20334$ Representative areas of the sections were selected at low power and then studied at $40 \times$ magnification. Cells were recognised as apoptotic bodies according to strict morphological criteria: cell shrinkage with retracted pink to orange cytoplasm, chromatin condensation and nuclear fragmentation, and separation of cells by a halo from adjacent enterocytes ${ }^{33-35}$ (fig 1A). Only isolated apoptotic bodies were counted; inflammatory reaction was absent. Intraepithelial lymphocytes were easily distinguished by their morphology and larger size. When a distinction could not be made between a lymphocyte and an apoptotic body, it was not counted.

Apoptotic index (AI) at the base of the crypt was assessed from the lowermost cell up to 20 cell positions along each side of the crypt ("proliferative compartment"). The number of apoptotic cells was counted and divided by the total number of epithelial cells in the proliferative compartment. The AI was determined for all longitudinal crypt sections in which the lumen of the crypt was completely visible. Only crypts in which extension of the crypt to the underlying muscularis mucosae was visible were included, ensuring only cells in the proliferative compartment of the crypt were counted. Crypts near a lymphoid aggregate, an inflammatory infiltrate, or nearby adenomatous epithelium were excluded.

Apoptotic index of surface epithelium was quantified by counting apoptotic cells at the luminal surface of the epithelium between crypts and dividing by the total number of epithelial cells at the luminal surface. The AI was determined for all luminal surfaces that consisted of one cell layer in the studied slide. Luminal surface covering a lymphoid aggregate, an inflammatory infiltrate, or nearby adenomatous epithelium was excluded.

The effect of sulindac on compartmentalisation of apoptosis was evaluated by analysing the apoptotic ratio (AI of crypt base divided by $\mathrm{AI}$ of surface).

IMMUNOHISTOCHEMISTRY FOR APOPTOTIC RELATED PROTEINS

Immunohistochemistry for $\mathrm{p} 21 / \mathrm{WAF}-1, \mathrm{bcl}-2$, bax, and p53 protein expression and compartmentalisation was performed on the same formalin fixed paraffin wax embedded specimens of grossly normal colorectal mucosa as used for apoptotic counting. Immunohistochemistry was performed as described previously ${ }^{36} 37$ using citrate buffer for antigen enhancement and with final detection through standard avidin-biotin staining methods. The monoclonal antibodies DO7 (Dakopatts, Glostrup, Denmark) at a dilution of $1 / 200$, Ab-1 (Oncogene Science, Cambridge, Massachusetts) at a dilution of $1 / 25$, and Oncoprotein 124 (Dakopatts, Glostrup, Denmark) at a dilution of 1/50 were used for the detection of mutated p53, expression of $\mathrm{p} 21 / \mathrm{WAF} 1$, and expression of bcl-2, respectively. Biotinylated rabbit antimouse (Dakopatts, Glostrup, Denmark) was used as secondary antibody. The protein bax was detected using the polyclonal rabbit IgG p19 (Santa Cruz Biotechnology Inc.) at a dilution of $1 / 100$ and with a biotinylated swine antirabbit (Dakopatts, Glostrup, Denmark) as secondary antibody. Primary antibodies were replaced with phosphate buffered saline (PBS) 
in negative control slides. Positive controls used were normal colon (p21/WAF-1), lymphoid infiltrates in the studied colorectal biopsy specimens (bcl-2), Paneth cells in small intestine (bax), and a known p53 positive colorectal carcinoma.

p21/WAF-1, bcl-2, bax, and p53 were evaluated in colorectal mucosa as described elsewhere. ${ }^{23}{ }^{24}$ Coded slides were scored by two observers (GJAO, JJK) in a blinded fashion
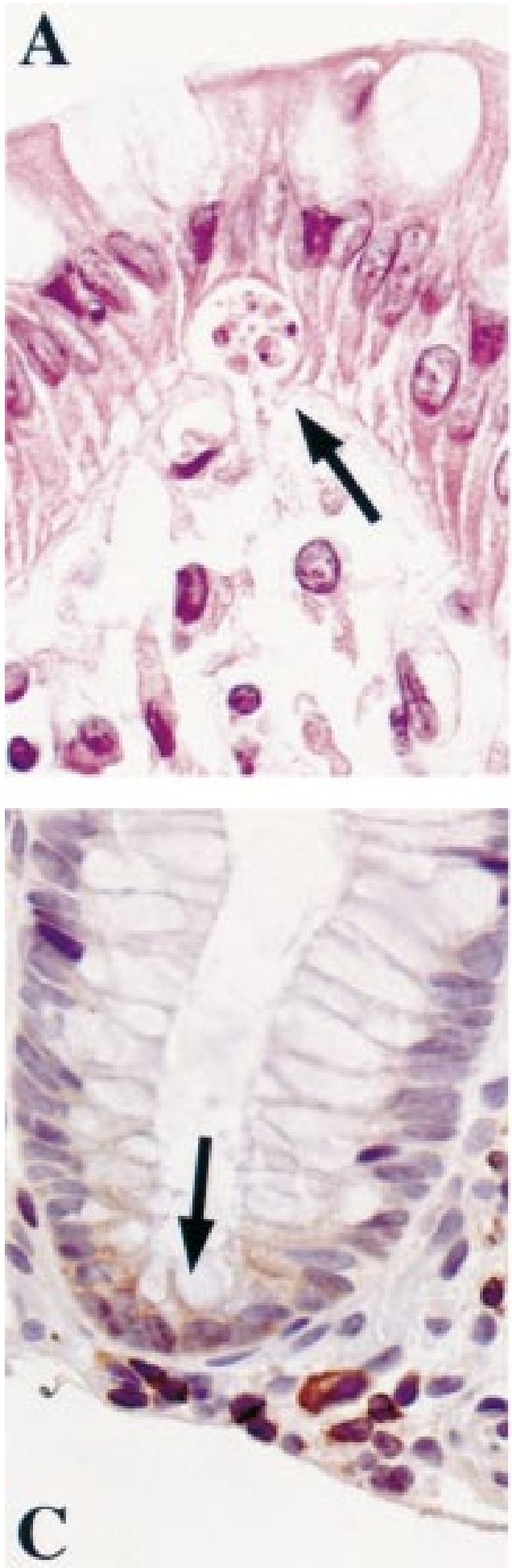

using light microscopy at $25 \times$ magnification. p21/WAF-1, bcl-2, bax, and p53 expression in the surface epithelium and in the proliferative compartment at the base of the crypts were graded semiquantitatively using a scale from 1 (no expression) to 4 (intense staining).

STATISTICAL ANALYSIS

The major statistical endpoint evaluated in this study was the effect of sulindac treatment on
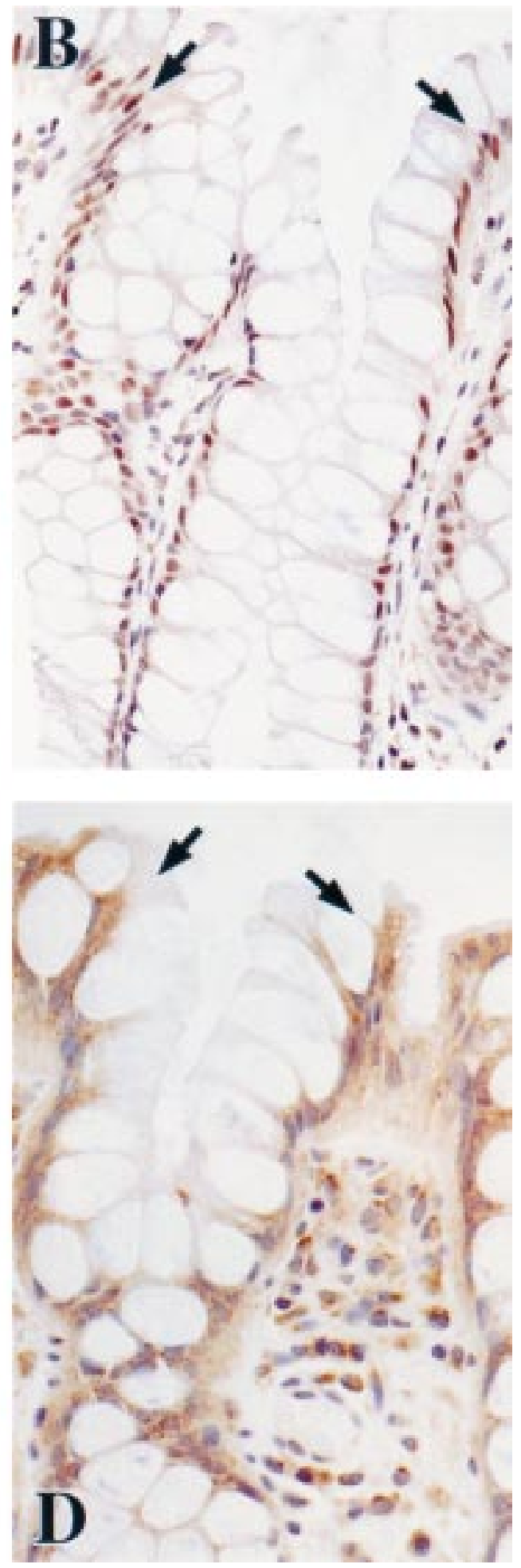

Figure 1 (A) Apoptotic cell with chromatin condensation, separation of the cell from adjacent enterocytes, formation of apoptotic body, cytoplasmic swelling. (B) WAF-1/p21 expression. (C) bcl-2 expression. (D) bax expression. 
Table 1 Mean percentage changes in apoptotic ratios by treatment group

\begin{tabular}{|c|c|c|c|c|c|c|}
\hline & \multicolumn{3}{|c|}{ Sulindac } & \multicolumn{3}{|c|}{ Placebo } \\
\hline & No & $\begin{array}{l}\text { Mean } \\
\text { \% change }\end{array}$ & $S D$ & No & $\begin{array}{l}\text { Mean } \\
\% \text { change }\end{array}$ & $S D$ \\
\hline All patients & 10 & -8 & 22 & 11 & +25 & 16 \\
\hline Intact colon & 5 & -16 & 13 & 7 & +31 & 13 \\
\hline Retained rectum & 5 & -0.3 & 28 & 4 & +15 & 18 \\
\hline
\end{tabular}

apoptosis. Apoptotic bodies in crypts in the proliferative compartment and within cells of the surface epithelium were studied. Data were collected for each patient at baseline and three months after receiving either sulindac or placebo treatment. Apoptotic indexes (number of apoptotic bodies divided by the total number of counted cells) were calculated for base of crypts and for surface epithelium. The apoptotic ratio (AR) was the ratio of these two numbers.

Statistical comparisons of changes in polyp number, apoptotic ratio, and protein expression were done using the non-parametric Wilcoxon rank sum test. To evaluate interaction effects (whether the sulindac effect differed in subjects with intact colons or rectal stumps), changes in these measures were treated as continuous variables in standard regression models. ${ }^{38}$ Because some of the pretreatment apoptotic ratios were zero, regression modelling of the relative AR change required a transformation of the apoptotic ratio, adding 1 to both the pretreatment and post-treatment ratios: [(post-treatment $\mathrm{AR}+1)-$ (pretreatment AR + 1)]/(pretreatment AR + 1). All statistical computations were performed using the SAS (Statistical Analysis System), ${ }^{39}$ and all $\mathrm{p}$ values reported are two sided.

\section{Results}

CLINICAL EFFECT OF SULINDAC

The mean percentage change in polyp number from baseline was significantly decreased in the sulindac group $(-46 \%)$ compared with the placebo group $(+13 \% ; \mathrm{p}=0.005)$; change in polyp number (SD) was $-11.5(16.5)$, range -58 to 9 in the sulindac group, and 0.09 (16.6), range -33.0 to 29.0 in the placebo group. Sample size was too small to make reliable conclusions concerning differences in effect of sulindac on patients with intact colons compared with those with retained rectums.

APOPTOSIS

The mean number of crypts counted in each patient was 12.7 (range 4-32). The total number of cells counted in the sulindac group was 14283 pretreatment and 12010 posttreatment. In the placebo group, 13438 and 12539 were counted, respectively.

A significant decrease in AR (AI base/AI surface) was noted in the sulindac group following treatment at three months (table 1, fig 2). The mean percentage change in AR was $-8 \%$ in the sulindac group and $+25 \%$ in the patients on placebo $(\mathrm{p}=0.004)$; change in apoptotic ratio was $-0.13(0.29)$, range -0.58 to 0.48 in the sulindac group, and $0.29(0.19)$, range -0.02 to 0.61 in the placebo group. In

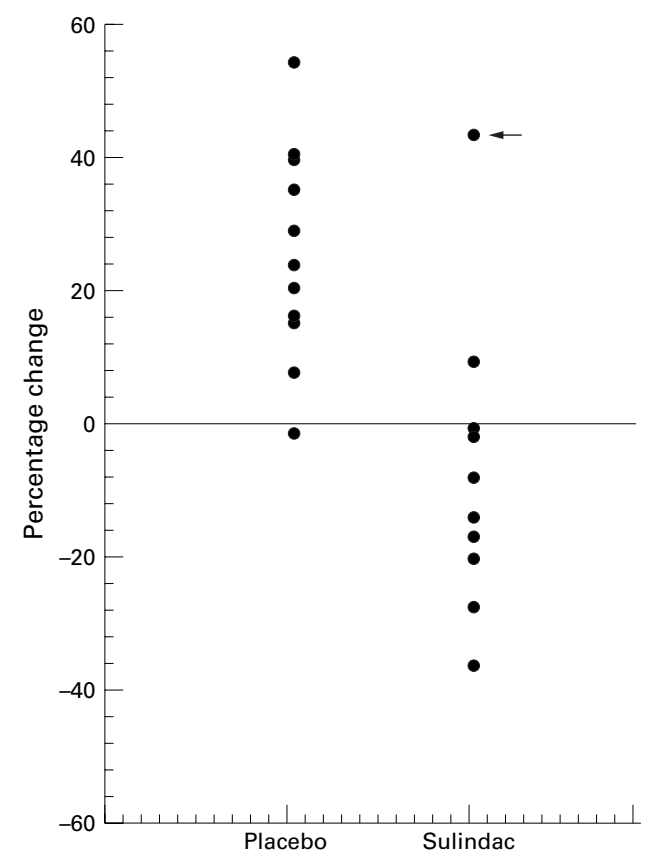

Figure 2 Decrease in apoptotic ratio with relatively greater apoptosis at the luminal surface compared with the base of the crypt seen in patients treated with sulindac compared with controls. Biopsy specimens were taken from the flat, normal appearing colorectal mucosa. Arrow indicates the patient who developed rectal cancer while on treatment with sulindac.

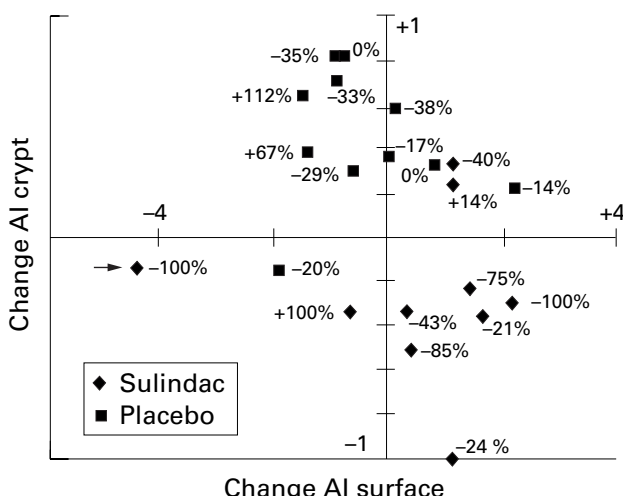

Figure 3 Change in apoptotic index at surface ( $x$ axis) plotted against change in apoptotic index at crypt (y axis) per patient treated with sulindac or placebo. Each observation is labelled with the change in polyp number. Arrow indicates the patient who developed rectal cancer while on treatment with sulindac.

the sulindac treated patients, change in AR was due to an increase of apoptosis at the surface and a decrease in the lower part of the crypt (fig 3).

APOPTOSIS RELATED PROTEIN EXPRESSION

Table 2 and fig 1 summarise p21/WAF1, bcl-2, bax, and p53 protein expression in FAP patients in the sulindac and placebo groups pretreatment and post-treatment. p21/WAF1 was expressed in the nuclei at the luminal surface and the upper third of the crypts (fig 1B). No expression in the proliferative compartment was noted. Cytoplasmic bcl-2 staining was confined to cells in the crypt base (fig 1C). Only sporadic, faint staining of the surface epithelium occurred. Cytoplasmic bax staining was strongest at the luminal surface as 
Table 2 Median (range) protein expression and localisation in patients treated with sulindac and placebo

\begin{tabular}{lllllll}
\hline & & \multicolumn{2}{l}{ Sulindac } & & \multicolumn{2}{l}{ Placebo } \\
\cline { 3 - 3 } & & Before & After & & Before & After \\
\hline bcl-2 & Base & $3(2-3)$ & $3(2-3)$ & & $2.5(2-3)$ & $2.5(2-3)$ \\
& Surface & $1(1-2)$ & $1(1-2)$ & & $1.5(1-2)$ & $1(1)$ \\
bax & Base & $2(2)$ & $2(1-2)$ & & $1.5(1-2)$ & $1.5(1-2)$ \\
& Surface & $3(3-4)$ & $3(2-4)$ & & $2.5(2-3)$ & $2.5(2-3)$ \\
p21 & Base & $1(1)$ & $1(1)$ & & $1(1)$ & $1(1)$ \\
& Surface & $3.5(2-4)$ & $3(3-4)$ & & $3(3-4)$ & $3(3-4)$ \\
p53 & Base & $1(1)$ & $1(1)$ & & $1(1)$ & $1(1)$ \\
& Surface & $1(1)$ & $1(1)$ & & $1(1)$ & $1(1)$ \\
\hline
\end{tabular}

p21 was only expressed in the upper third of the crypt and at the luminal surface; no p53 expression was seen. No statistical differences were noted by Wilcoxon paired rank sum test.

compared with the base of the crypts (fig 1C). There were no differences in expression of WAF-1/p21, bcl-2, or bax before or after treatment with sulindac. The $\mathrm{p} 53$ gene product was not over expressed in normal colorectal mucosa of any patient before or after treatment with sulindac.

\section{Discussion}

Results of numerous investigations have concluded that NSAIDs are chemoprotective agents against colorectal tumorigenesis. ${ }^{1}$ The mechanism of chemoprevention of NSAIDs remains unclear, but emerging evidence suggests an effect of these drugs on apoptotic pathways in colorectal epithelial cell kinetics. Previously, we reported that sulindac produced colorectal adenoma regression in patients with familial adenomatous polyposis and affected epithelial cell apoptosis but not proliferation in their colorectal mucosa. ${ }^{29}$ The lack of effect of sulindac on colorectal cell proliferation in FAP patients has also been noted by others. ${ }^{30}$ In addition, both animal and cell culture experiments have confirmed the chemopreventive property of sulindac and the ability of this agent to induce apoptosis. ${ }^{32} 40-45$

In normal colorectal mucosa, proliferation and apoptosis occur in well defined zones. Proliferating cells are restricted to the lower two thirds of the crypt, ${ }^{17}$ whereas apoptosis occurs principally at the luminal surface between crypts. ${ }^{18-20}$ Importantly, in FAP patients alterations in cell kinetics in normal appearing flat colorectal mucosa are noted with upward shift of the proliferative compartment and decreased surface apoptosis, ${ }^{17}{ }^{21}$ the earliest changes noted in adenoma formation. Therefore, in the present study, the compartmentalisation of apoptosis was evaluated in patients with familial adenomatous polyposis before and after treatment with sulindac in comparison to placebo. In patients who had sulindac induced regression of colorectal adenomas, alteration of the colorectal mucosal apoptotic ratio with relative increase in apoptosis in surface epithelium compared with crypt base was noted. This shift towards apoptosis in the surface epithelium is consistent with normal epithelial cell kinetics and discordant with the pattern noted in the adenoma-carcinoma sequence in which apoptosis is reduced at the surface epithelium of adenomas and occurs more frequently at the base of the adenomatous crypt. ${ }^{2022}$
The findings in the present study are consistent with the observations of Mahmoud et $a l$ in the MIN mouse model of familial adenomatous polyposis. ${ }^{31}$ Histologically normal MIN intestinal epithelium exhibits elevated B catenin expression associated with aberrant proliferation and apoptosis and a decreased rate of enterocyte crypt-villus migration. Tumour preventing doses of sulindac sulphide normalised enterocyte proliferation and apoptosis and restored a normal enterocyte migration pattern. The reason for the lack of normalisation of proliferation in some human studies remains unclear.

In normal colonic crypts, epithelial cell growth and function depend on a finely tuned homoeostasis of cell proliferation, migration, differentiation, and apoptosis. The APC protein seems to play a crucial role in this process through interaction with $\mathrm{B}$ catenin. APC controls B catenin by binding and phosphorylation, resulting in breakdown of the $\mathrm{B}$ catenin protein. ${ }^{46} \mathrm{~B}$ catenin is a component of the adherens junction, a cadherin associated transmembrane complex mediating cell adhesion and a possible pathway through which the APC protein modulates cell migration. ${ }^{47}$ Moreover, $\mathrm{B}$ catenin binds to the DNA binding proteins Tcf and Lef which alter expression of genes regulating cell proliferation and apoptosis, and APC inhibits B catenin/Tcf mediated transcription. ${ }^{48-50}$ Also, when only one allele is lost through germline mutation, the above functions of APC seem to be compromised already, both in humans and in MIN mice. ${ }^{31}$ Although the precise mechanism is unknown, the functions of the APC protein appear restored by sulindac sulphide. ${ }^{51}$ Induction of apoptosis correlates with cyclooxygenase 2 inhibition by sulindac, with subsequent increase in lipid compounds including ceramide which induces apoptosis. ${ }^{52}$

The apoptotic ratio in the colorectal mucosa proved useful in distinguishing patients on and off sulindac treatment. Of particular interest is a 24 year old woman treated with sulindac who developed colorectal cancer with concomitant complete regression of adenomas. Similar to other patients with adenoma resolution, biomarkers including mucosal prostaglandin concentrations dropped dramatically with sulindac therapy. ${ }^{53}$ But in contrast, the apoptotic ratio in this patient's colorectal mucosa revealed no change from presulindac treatment, a finding strikingly different from the others with adenoma regression (fig 2). Consequently, the value of the apoptotic ratio as an intermediate biomarker deserves further investigation.

The present study failed to find that the changes in the apoptotic ratio were accompanied by differences in expression or compartmentalisation of WAF- $1 / \mathrm{p} 21$, bcl-2, bax, or p53 proteins between sulindac and placebo treatment groups. Similarly, other investigators utilising in vitro models have reported that sulindac induced apoptosis is independent of bcl-2 expression and the integrity of the p53 tumour suppressor pathway. ${ }^{32} 4054$ However, Goldberg et al found increased levels of p21 and reduced levels of mutant p53 in the HT29 
colon cancer cell line after exposure to sulindac. Yet, these effects appeared to occur independent of the ability of sulindac to induce apoptosis and were not associated with cell differentiation..$^{56} \mathrm{~A}$ recent study showed influence of low dose sulindac on expression of the p53 tumour suppressor gene and bcl-2, but these investigators utilised different methodology. ${ }^{57}$ Although no differences in expression or compartmentalisation of specific gene expression was noted in our study, smaller differences may have been missed by the immunohistochemical methodology utilised, the small number of patients studied, or the small number of categories evaluated.

In summary, this study provides evidence in humans that sulindac interferes with the regulation of rectal epithelial cell kinetics by altering the apoptotic ratio in the rectal epithelium. Additionally, the apoptotic ratio may be a useful intermediate biomarker in the study of colorectal tumorigenesis.

This work was supported in part by The Clayton Fund, The Netherlands Digestive Disease Foundation (ws 97-75), and NIH grant CA53801, CA93-16, and CA62924. GJA Offerhaus is supported by the Queen Wilhelmina Fund, Dutch Cancer Foundation for visiting professorship at The Johns Hopkin University School of Medicine. J Keller was also supported by the Oueen Wilhelmina Fund for a research elective at The Johns Hopkins Medical Institutions. The authors thank Ms Linda M Welch for secretarial support, Dr Annemarie Cleton-Jansen for critically reading the manuscript and for providing helpful suggestions, and Merck Sharp and Dohme for donating sulindac and placebo.

1 Giardiello FM, Offerhaus GJA, DuBois RN. Role of nonsteroidal drugs in colon cancer prevention. Eur f Cancer 1995;31A: 1071-6.

2 Hial V, Demello MC, Horakova Z, et al. Antiproliferative activity of antiinflammatory drugs in two mammalian cell

3 Bulture cell lines. F Pharmacol Exp Ther 1977;202:446-54. ibly inhibits cell growth in the G1 phase of the cell cycle. Biochem Pharmacol 1979;28:441-3.

4 Bayer BM, Kruth HS, Vaughan M, et al. Arrest of cultured cells in the G1 phase of the cell cycle by indomethacin. Pharmacol Exp Ther 1979;210:106-11.

5 Pollard M, Luckert PH. Indomethacin treatment of rats ( Treat Rep 1980;64:1323-7.

6 Moorghen M, Ince P, Finney KJ, et al. A protective effect of sulindac against chemically-induced primary colonic tusulindac against chemically-induced
mors in mice. F Pathol $1988 ; 156: 341-7$.

7 Skinnner SA, Penny AG, O'Brien PE. Sulindac inhibits the rate of growth and development of colon tumors in the rat rate of growth and development of colon tu

8 Reddy BS, Rao CV, Rivenson A, et al. Inhibitory effect of aspirin on azoxymethane-induced colon carcinogenesis in F344 rats. Carcingenesis 1993:14:1493-7.

9 Jacoby RF, Marshall DJ, Newton MA, et al. Chemoprevention of spontaneous intestinal adenomas in APC Min mouse model by the nonsteroidal antiinflammatory drug piroxicam. Cancer Res 1996;56:710-15.

10 Thun M, Namboodiri M, Heath C. Aspirin use and reduced risk of fatal colon cancer. N Engl f Med 1991;325:1593-6.

11 Giovannucci E, Rimm EB, Stampfer MJ, et al. Aspirin use and risk for colorectal cancer and adenoma in male health professionals. Ann Intern Med 1994;121:241-6.

12 Waddell WR, Loughry RW. Sulindac for polyposis of the colon. 7 Surg Oncol 1983;24:83-7.

13 Rigau J, Pique JM, Rubio E, et al. Effects of long-term sulindac therapy on colonic polyposis. Ann Intern Med dac therapy on

14 Labayle D, Fischer D, Vielh P, et al. Sulindac causes regression of rectal polyps in familial adenomatous polyposis. Gastroenterology 1991;101:635-9.

15 Giardiello FM, Hamilton SR, Krush AJ, et al. Treatment of colonic and rectal adenomas with sulindac in familial adenomatous polyposis. $N$ Engl f Med 1993;398:1313-16.

16 Nugent KP, Farmer KCR, Spigelman AD, et al. Randomized controlled clinical trial of sulindac on intestinal polyposis in FAP. Br f Surg 1993;80:1618-19.

17 Lipkin $M$. Phase 1 and phase 2 proliferative lesions of colonic epithelial cells in diseases leading to colonic cancer. Cancer 1974;34:878-88.

18 Moss SF, Scholes JV, Holt PR. Abnormalities of epithelial apoptosis in multistep colorectal neoplasia demonstrated 1996;41:2238-47.
19 Hall PA, Coates PJ, Ansari B, et al. Regulation of cell number in the mammalian gastrointestinal tract: the importance of apoptosis. F Cell Sci 1994;107:3569-77.

20 Sinicrope FA, Roddey G, McDonell TJ, et al. Increased apoptosis accompanies neoplastic development in the

21 Bedi A, Pasricha PJ, Akhtar AJ, et al. Inhibition of apoptosis during development of colorectal cancer. Cancer Res 1995; 55:1811-16

22 Moss SF, Liu TC, Petrotos A, et al. Inward growth of colonic adenomatous polyps. Gastroenterology 1996;111: $1425-32$.

23 Krajewski S, Krajewski M, Shabaik A, et al. Immunohistochemical determination of in vivo distribution of Bax, a dominant inhibitor of Bcl-2. Am $\mathcal{F}$ Pathol 1994;145:1323-36.

24 Polyak K, Hamilton SR, Vogelstein B, et al. Early alterations of cell-cycle-regulated gene expression in colorectal neoplasia. Am ₹ Pathol 1996;149:381-7.

25 Mosnier J-F, Perret AG, Vindimian M, et al. An immunohistochemical study of the similtaneous expression of Bcl-2 and p53 oncoproteins in epithelial tumors of the colon and rectum. Arch Pathol Lab Med 1996;120:654-9.

26 Baretton GB, Diebold J, Christoforis G. Apoptosis and immunohistochemical bcl-2 expression in colorectal adenomas and carcinomas. Cancer 1996;77:255-64

27 Sinicrope FA, Ruan SB, Cleary KR, et al. bcl-2 and p53 oncoprotein expression during colorectal tumorigenesis. Cancer Res 1995;55:237-41

28 Mills SJ, Shepherd NA, Hall PA, et al. Proliferative compartment deregulation in the non-neoplastic colonic epithelium of familial adenomatous polyposis. Gut 1995; 36:391-4.

29 Pasricha PJ, Bedi A, O'Connor K, et al. The effects of sulindac on colorectal proliferation and apoptosis in familial adenomatous polyposis. Gastroenterology 1996;109:994-8.

30 Spagnesi MT, Tonelli F, Dolara P, et al. Rectal proliferation and polyp occurrence in patients with familial adenomatous polyposis after sulindac treatment. Gastroenterology 1994;106:362-6.

31 Mahmoud NN, Boolbol SK, Bilinski RT, et al. APC gene mutation is associated with a dominant-negative effect upon intestinal cell migration. Cancer Res 1997;57:504550 .

32 Piazza GA, Rahm AK, Finn TS, et al. Apoptosis primarily accounts for the growth-inhibitory properties of sulindac metabolites and involves a mechanism that is independent of cyclooxygenase inhibition, cell cycle arrest, and p53 induction. Cancer Res 1997;57:2452-9.

33 Wyllie AH, Kerr JFR, Currie AR. Cell death: the significance of apoptosis. Int Rev Cytol 1980;68:251-306.

34 van de Schepop HAM, de Jong JS, van Diest PJ, et al. Counting of apoptotic cells: a methodological study in invasive breast cancer. 7 Clin Pathol Mol Pathol 1996;49: M214-17.

35 Kerr JFR, Wyllie AH, Currie AR. Apoptosis: a basic biological phenomenon with wide-ranging implications in tissue kinetics. Br f Cancer 1972;26:239-57.

36 Slebos RJC, Baas IO, Clement M, et al. Clinical and pathological associations with $\mathrm{p} 53$ tumor suppressor gene mutations and expression of $\mathrm{p} 21 / \mathrm{waf} 1 / \mathrm{cip} 1$ in colorectal carcinoma. Br f Cancer 1996;74:165-71.

37 Baas IO, Mulder JWR, Offerhaus GJA, et al. An evaluation of six antibodies for immunohistochemistry of mutant p 53 gene product in archival colorectal neoplasms. 7 Pathol $1994 ; 172: 5-12$.

38 Giardiello FM, Offerhaus GJA, Tersmette AC, et al. Sulindac-induced regression of colorectal adenomas in familial adenomatous polyposis: evaluation of predictive factors. Gut 1996;38:578-81.

39 SAS Institute Inc. SAS User's Guide: Statistics, Version 5. Cary, NC: SAS Institute Inc., 1985

40 Piazza G, Rahm A, Pamukcu R, et al. Induction of apoptosis by sulindac metabolites involves a p 53 and bcl- 2 independent mechanism and does not require cell cycle arrest [abstract]. Gastroenterology 1996;110:A577.

41 Piazza G, Rahm ALK, Krutzch M, et al. Antineoplastic drugs sulindac sulfide and sulfone inhibit cell growth by inducing apoptosis. Cancer Res 1995;55:3110-16.

42 Rao CV, Rivenson A, Simi B, et al. Chemoprevention of colon carcinogenesis by sulindac, a nonsteroidal antiinflammatory agent. Cancer Res 1995;55:1464-72.

43 Samaha HS, Kelloff GJ, Steele V, et al. Modulation of apoptosis by sulindac, curcumin, phenylethyl-3-methylcaffeate, and 6-phenylhexyl isothiocyanate: apoptotic index as a biomarker in colon cancer chemoprevention and promotion. Cancer Res 1997;57:1301-5.

44 Shiff SJ, Qiao L, Tsai L-L, et al. Sulindac sulfide, an aspirinlike compound, inhibits proliferation, causes cell cycle quiesence, and induces apoptosis in HT-29 colon adenocarcinoma cells. $\mathcal{F}$ Clin Invest 1995;96:491-503.

45 Chan TA, Morin PJ, Vogelstein B, et al. Mechanisms underying unsteroidal antiinflammatory drug-mediated apoptosis. Proc Natl Acad Sci USA 1998;95:681-6.

46 Bullions LC, Levine AJ. The role of beta catenin in cell adhesion signal transduction and cancer. Curr Opin Oncol 1998;10:81-7.

47 Hermiston ML, Wong MH, Gordon JI. Forced expression of E-cadherin in the mouse intestinal epithelium slows cell migration and provides evidence for nonautonomous regulation of cell fate in a self-renewing system. Genes Dev 1996;10:985-99.

48 Korinek V, Barker N, Morin PJ, et al. Constitutive transcriptional activation by a beta-catenin-Tcf complex in APCcolon carcinoma. Science 1997;275:1784-7. 
49 Morin PJ, Sparks AB, Korinek V, et al. Activation of beta-catenin tcf signaling in colon cancer by mutations in beta-catenin tcf signaling in colon cancer by mut
beta-catenin or APC. Science 1997;275:1787-81.

50 Sparks AB, Morin PJ, Vogelstein B, et al. Mutational analysis of the APC/beta-catenin/Tcf pathway in colorectal cancer. Cancer Res 1998;58:1130-4.

51 Morin P, Vogelstein B, Kinzler KW. Apoptosis and APC in colorectal tumorigenesis. Proc Natl Acad Sci 1996;93:79504 .

52 Chan TA, Morin PJ, Vogelstein B, et al. Mechanisms underlying nonsteroidal antiinflammatory drug-induced apoptosis. Proc Natl Acad Sci 1998;95:681-6.

53 Giardiello FM, Spannhake EW, DuBois RN, et al. Prostaglandin levels in human colorectal mucosa: effects of sulindac in patients with familial adenomatous polyposis. Dig Dis Sci 1998;43:311-16.
54 Hanif R, Pittas A, Feng Y, et al. Effects of nonsteroidal antiinflammatory drugs on proliferation and on induction of apoptosis in colon cancer cells by a prostaglandinindependent pathway. Biochem Pharmacol 1996;52:237-45.

55 Arber N, Kyu-Ho Han E, Sgambata A, et al. A K-ras oncogene increases resistance to sulindac-induced apoptosis in rat enterocytes. Gastroenterology 1997;113:1892-900.

56 Goldberg Y, Nassif II, Pittas A, et al. The anti-proliferative effect of sulindac and sulindac sulfide on HT-29 colon cancer cells: alterations in tumor suppressor and cell cycleregulatory proteins. Oncogene 1996;12:893-901.

57 Winde G, Schmid KW, Brandt B, et al. Clinical and genomic influence of sulindac on rectal mucosa in familial adenomatous polyposis. Dis Colon Rectum 1997;40:115669. 